\title{
From Flush to Energy Model: Solution of World's Biggest Open Toilet (Indian Railways)
}

\author{
Virendra Kumar Yadav \\ School of Computer Engg. \\ KIIT University, Bhubaneswar \\ Odisha, India
}

\author{
Saumya Batham \\ School of Computer Engg. \\ KIIT University, Bhubaneswar \\ Odisha, India
}

\author{
Amit Kumar Mallik \\ School of Computer Engg. \\ KIIT University, Bhubaneswar \\ Odisha, India
}

\begin{abstract}
Indian Railways was being roundly criticized for creating an environment hazard by discharging toilet waste on tracks. IR coaches have toilet system that has hole on the floor through which human feces and urine is flushed directly on railway tracks. Various types of environment friendly Green toilets have put on outfields trials by Indian Railways to overcome this problem. Controlled Discharge Toilet System (CDTS), Bio-toilet developed by Indian Railways engineers and DRDO biotechnologists, development of Zero Discharge Toilet System (ZDTS) by IIT Kanpur and Research Development and Standards Organization (RDSO) Lucknow, are some efforts in this direction. These technologies are more expensive due to inherent complexities, disposal problem at yards (ZDTS) and requirement of extra infrastructure at the terminal. FFEM approach not only solves these problems but also convert toilet waste into energy which can be utilized further in lighting at platforms or some other useful purposes.
\end{abstract}

\section{General Terms}

Expert System

\section{Keywords}

Flush Expert Device (FED), Signal Indicator (SI), Biogas Plant, Temporary Storage Tank (TST), Septic Tank Expert Device (STED), Minimum Filled Level (MFL)

\section{INTRODUCTION}

Indian Railways represent the pride of an Indian. Indian Railways is an Indian state-owned enterprise, owned and operated by the government of India through the Ministry of Railways. Railways have been good medium of transportation for its passengers since 1851 when it was introduced in India (Bombay to Thane). During these 150 years, it has approximately touched each and every part of the country. It covers about $1,15,000 \mathrm{~km}$ with 7500 stations [1]. As of December 2012, it transported over 25 million passengers daily. Indian Railways is known to be Asia largest railway network with modern coaches with water and lavatory facility, technological self-sufficiency, long distances sleeper class and a variety of air-conditioned and non-air-conditioned services to suit every pocket of its passengers.

Indian Railways uses more than 40,000 coaches regularly for passenger service. Keeping this population of the coaches in view, IR has to operate approximately 1,60,000 toilets, round the clock, on coaches moving at a speed of $100 \mathrm{kmph}$ plus. The toilets on Indian Railways are of open flush type in which faecal matter excreted by passenger is discharged directly on the tracks. Human feces and urine contains a large number of harmful germs. These germs not only pollutes the surrounding environment but also responsible for causing parasitic infections (tapeworm, pinworm, roundworm and hookworm are spread mainly through human solid waste), hepatitis, diarrhoea, waterborne diseases, typhoid, cholera and other various types of diseases [2]. Indian Railways has completed more than 150 glorious years developing in many aspects but neglecting one major area, disposal of human faecal matter in large amount on tracks by toilets installed on coaches of Indian railways. This area has neglected by every responsible authority during these 150 years, which is now a great cause of concern. Practicing such mechanism in toilet system flouts many Act such as Indian penal Code, 1860, Hazardous wastes (Management and Handling) Rules, 1989, Environment Protection Act, 1986 and Code of Criminal Procedure,1973 [3].

This paper proposes an approach FFEM (From Flush to Energy Model) that not only give solution to world's biggest open toilet but also utilizes the toilet waste to generate the environment friendly energy, Biogas energy. This biogas energy can be utilized in lighting or some other useful purposes according to the need. This paper is organized as follows. In section 2 we introduce related works in this direction. Section 3 includes the concept of FFEM. Section 4 gives the proposed algorithm and section 5 concludes the paper.

\section{RELATED WORKS}

Due to heavy number of travelers, Indian Railways is suffering by a very sophisticated problem that is human waste disposal in running trains without any treatment. Several models and techniques were proposed to solve the Indian Railways toilet problems.

Controlled Discharge toilet System (CDTS) discharges waste on the run only after the train speed reaches $30 \mathrm{kmph}$. CDTS used a sophisticated system that used GPS. Discharge takes place away from the station, helping in keeping the station clean. Another effort in this direction is Zero Discharge Toilet System (ZDTS). ZDTS was developed by IIT Kanpur and Research Development and Standards Organization (RDSO), Lucknow. ZDTS segregate solid waste and liquid waste, recycling the liquid waste to be used for flushing. Solid waste is to store in a box and treated with anaerobic bacteria. The box is to empty at stations or yards. IR Engineers and DRDO biotechnologists developed Bio-toilet. The technology being developed uses special strains of bacteria to biodegrade human waste into harmless and odourless products. Several other efforts are also in hand in parallel such as vacuum toilet technology etc.

The proposed models and technologies have certain limitations in terms of money, inherent complexities, requirement of extra infrastructure at terminals, maintenance 
and several other factors. Controlled Discharge Toilet Systems were expensive, costing around 6 lakh per piece [4]. Removing solid waste from tanks was a problem (ZDTS), Vacuum machines are prone to technical glitches [4].

\section{PROPOSED WORK}

Concept of proposed method is explained in this section. Section 3.1 and section 3.2 explain the construction concept and working concept respectively.

\subsection{Construction Concept}

To implement this model we need TST (Temporary Storage Tank), Open/Close signal indicator, Flush Expert Device (FED), septic tanks, Biogas Plant.

First we have to install TST and FED to each Railway coach. Also we need to connect toilet outlet (hole in the floor as in Indian Railway's toilet system) to inlet of TST. Outlet of TST is controlled by FED. Each coach of train has Open/Close signal receiver. We have to construct septic tanks which have open and close mechanism controlled by Septic Tank Expert Device (STED). The outlet of septic tank is connected to Biogas plant. Open/Close signal indicators have to install at the two ends of the septic tank.

\subsection{Working Concept}

In this section we will explain the working of FFEM (Fig 1). Suppose a train has installed all the devices needed and the required infrastructure is constructed successfully and is now ready for use. People board at station and they started using the toilets in their coaches. The feces and urine after each flush is collected in TST through connecting pipes. The TST also has open and close mechanism which is controlled by the FED. Train at their departure time will leave from platform. The Open/Close Signal Indicators have installed at some distance from the platform. When the train coach (say first coach) touches the first time Open/Close Signal Indicator, FED will receive a signal. On receipt of the signal by the FED device, device will check for the condition. The FED will check the MFL (Minimum Filled Level) in TST. If TST is filled above or equal to MFL, then it will generate a signal that will open the outlet of TST otherwise it does not generate the signal and outlet of TST remains close.

At the same time when the train coach touches the Open/Close signal indicator, one more signal is generated that will be received by STED. The STED on receiving this signal will open the doors of septic tanks. When the above procedure is performed successfully, TST will empty human feces and urine to septic tanks through outlet of TST to inlet doors of septic tanks. Second time when the coach (say first coach) touches the Open/Close signal indicators, again a signal is received by the FED. On receipt of this signal FED will close the outlet of TST. This mechanism is practiced for each individual coach. The STED once received the signal, will open the doors of septic tanks for fixed amount of time (according to need).After this fixed amount of time expires,
STED if does not receive any signal, it will close the septic tank doors. So practicing this mechanism will avoid the opening/closing of doors of septic tanks frequently. Now septic tank contains the human feces and urines. This solid waste (human feces and urines) which is collected in septic tanks is fed into biogas plant. This technique is practicing in various parts of the world now a day's [5] and easily available. In biogas plant when human faecal matter is treated with anaerobic bacteria (Biomethanation Process), microbial actions take place resulting in generation of biogas. This biogas can be utilized for electricity generation or other useful purposes. The left slurry after Biomethanation process can be collected from slurry tank as liquid fertilizer.

\section{PROPOSED ALGORITHM}

The proposed algorithm is as follows:

\subsection{FED algorithm}

Open:

1) Signal_Received (First Time)

2) \{

3) if (Tank_Filled $>=$ MFL)

4) \{

5) Outlet_TST = set.open

6) \}

7) else

8) \{

9) Outlet_TST = set.close;

10) \}

11) $\}$

12) end // the FED Open mechanism ends here

Close:

1) Signal_Received (Second Time)

2) \{

3) if (Outlet_TST = open)

4) \{

5) Outlet_TST = set.close;

6) \}

7) else

8) \{

9) do nothing;

10) \}

11) \}

12) end

\subsection{STED Algorithm}

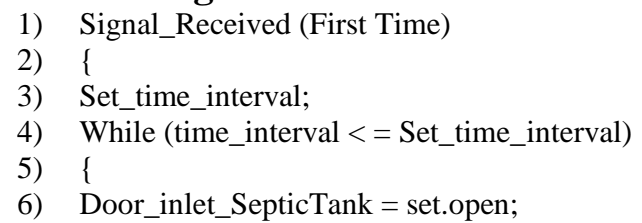




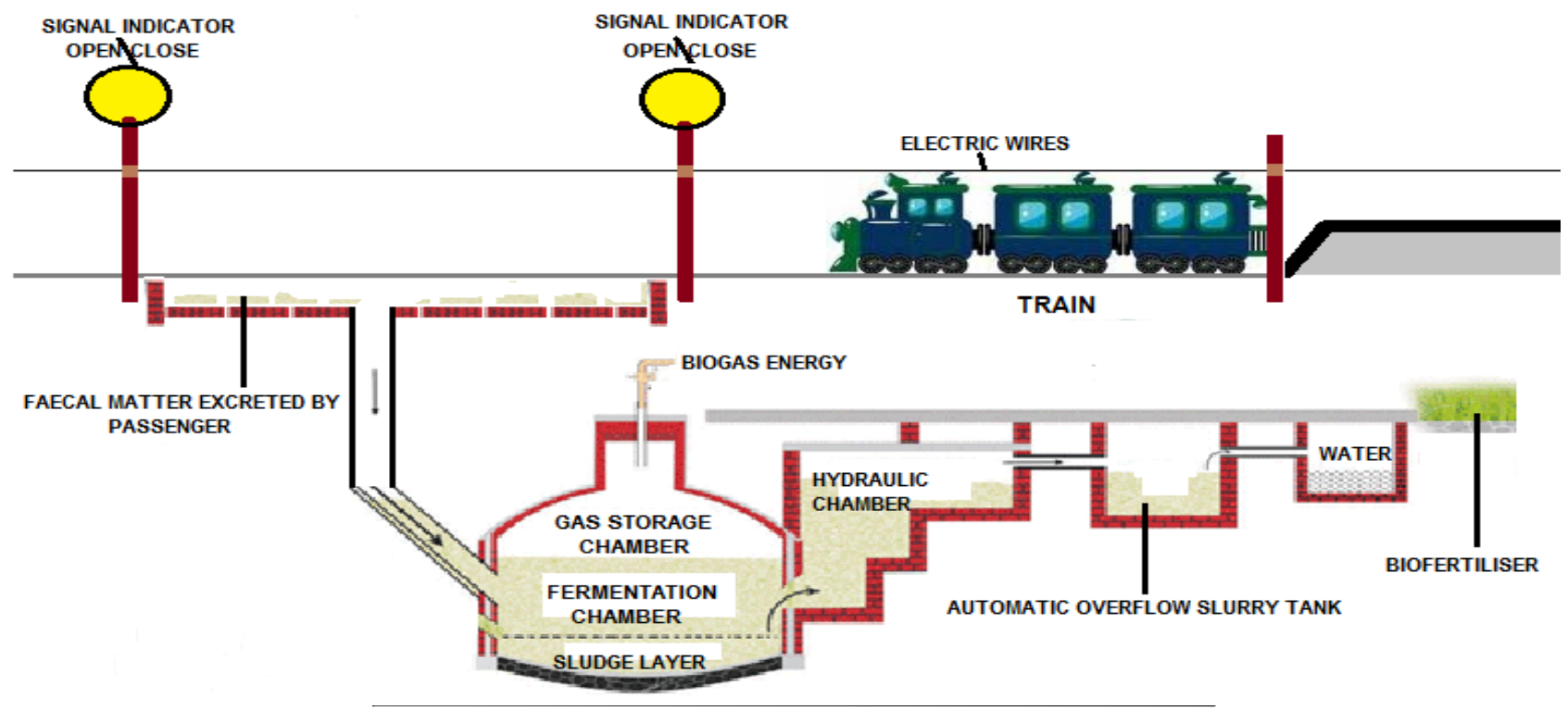

Fig 1: FFEM working model

7) time_interval ++;

8) $\}$

9) $\}$

10) end //the algorithm STED ends here

\section{CONCLUSION}

Sanitation in Indian Railways had become a need of time and an important aspect for Indian Railway's complete success. Responsible authorities are also putting efforts in this direction by carrying out outfield trials and putting notice board in toilets such as requesting passenger not to use flush when train is stationary at platform.

Our proposed model (FFEM) will not put any restriction on its user. Passengers can use toilet when they want, even if the train is standing on the platform. Also it converts human solid waste to biogas energy which can be utilized in lighting the lamp post at the platform (as requirement) or some other useful purposes. Approach of this model will not only solve the world's biggest open toilet problem (Indian Railways) but gives alternate source of energy.

\section{ACKNOWLEDGMENTS}

This work was supported by KIIT University, Bhubaneswar, Odisha. Our thanks to the experts Prof. Amitavo Sen, Prof. G. B. Mund, Prof. M. N. Das, Asst. Prof. Anuja Kumar Acharya, Mr. V. K. Yadav, Mr. A. K. Yadav and Mr. Sri Prakash for their valuable suggestions and time they provided to us.

\section{REFERENCES}

[1] Indian

http://en.wikipedia.org/wiki/Indian_Railways

Accessed on 02/03/2013).
[2] Dr. Manoj Hedaoo, Dr. Suchita Hirde, Ms. Arshi Khan "Sanitation in Indian Railways Premises: A great cause of concern" International Journal of Advanced Engineering Technology, IJAET/vol.III/issue I/ JanuaryMarch, 2012/ 50-55.

[3] Rediff News (January 28, 2007) "Indian Railways sued unhygienic waste disposal" http://www.rediff.com/news/report/rail/20070128.htm (Last Accessed on 04/03/2013).

[4] The Times of India (November 28, 2012) "Railways needs a bug to keep toilets clean" http://articles.timesofindia.indiatimes.com/2012-1128/chennai/35410640_1_toilet-system-discharge-toiletsindian-railways (Last Accessed on 03/02/2013).

[5] Smart Planet (October 7, 2010) "Human waste now heats British homes" www.smartplanet.com/blog/intelligent-energy/humanwaste-now-heats-british-homes/3020 (Last Accessed on 12/12/2012).

[6] Passenger train toilet en.wikipedia.org/wiki/Passenger_train_toilet (Last Accessed on 21/12/2012).

[7] Dell Social Innovation Challenge " A solution for better hygiene, sanitation, waste disposal, generation of bio-fuel and creation of jobs" http://www.dellchallenge.org/projects/clean2greensolutions (Last Accessed on 11/03/2013) 